ORIGINAL ARTICLE

\section{Effect of Aspirin on Cardiovascular Events and Bleeding in the Healthy Elderly}

\author{
J.J. McNeil, R. Wolfe, R.L. Woods, A.M. Tonkin, G.A. Donnan, M.R. Nelson, \\ C.M. Reid, J.E. Lockery, B. Kirpach, E. Storey, R.C. Shah, J.D. Williamson, \\ K.L. Margolis, M.E. Ernst, W.P. Abhayaratna, N. Stocks, S.M. Fitzgerald, \\ S.G. Orchard, R.E. Trevaks, L.J. Beilin, C.I. Johnston, J. Ryan, B. Radziszewska, \\ M. Jelinek, M. Malik, C.B. Eaton, D. Brauer, G. Cloud, E.M. Wood, S.E. Mahady, \\ S. Satterfield,* R. Grimm, and A.M. Murray, for the ASPREE Investigator Group $†$
}

ABSTRACT

\section{BACKGROUND}

Aspirin is a well-established therapy for the secondary prevention of cardiovascular events. However, its role in the primary prevention of cardiovascular disease is unclear, especially in older persons, who have an increased risk.

\section{METHODS}

From 2010 through 2014, we enrolled community-dwelling men and women in Australia and the United States who were 70 years of age or older (or $\geq 65$ years of age among blacks and Hispanics in the United States) and did not have cardiovascular disease, dementia, or disability. Participants were randomly assigned to receive $100 \mathrm{mg}$ of enteric-coated aspirin or placebo. The primary end point was a composite of death, dementia, or persistent physical disability; results for this end point are reported in another article in the Journal. Secondary end points included major hemorrhage and cardiovascular disease (defined as fatal coronary heart disease, nonfatal myocardial infarction, fatal or nonfatal stroke, or hospitalization for heart failure).

\section{RESULTS}

Of the 19,114 persons who were enrolled in the trial, 9525 were assigned to receive aspirin and 9589 to receive placebo. After a median of 4.7 years of follow-up, the rate of cardiovascular disease was 10.7 events per 1000 person-years in the aspirin group and 11.3 events per 1000 person-years in the placebo group (hazard ratio, 0.95 ; $95 \%$ confidence interval [CI], 0.83 to 1.08 ). The rate of major hemorrhage was 8.6 events per 1000 person-years and 6.2 events per 1000 person-years, respectively (hazard ratio, 1.38; 95\% CI, 1.18 to 1.62 ; $\mathrm{P}<0.001$ ).

\section{CONCLUSIONS}

The use of low-dose aspirin as a primary prevention strategy in older adults resulted in a significantly higher risk of major hemorrhage and did not result in a significantly lower risk of cardiovascular disease than placebo. (Funded by the National Institute on Aging and others; ASPREE ClinicalTrials.gov number, NCT01038583.)
The authors' full names, academic degrees, and affiliations are listed in the Appendix. Address reprint requests to Dr. McNeil at the Department of Epidemiology and Preventive Medicine, Monash University, 553 St. Kilda Rd., Melbourne, VIC 3004, Australia, or at john.mcneil@ monash.edu.

*Deceased

$†$ A complete list of the ASPREE trial investigators is provided in the Supplementary Appendix, available at NEJM.org.

This article was published on September 16, 2018, at NEJM.org.

N Engl J Med 2018;379:1509-18. DOI: $10.1056 /$ NEJMoal 805819 Copyright () 2018 Massachusetts Medical Society. 
$\mathrm{D}$ RAMATIC INCREASES IN LIFE EXPECtancy over the past century have led to a substantial demographic shift toward an aging society in many countries. Thus, maintaining good health in older persons is an increasingly important public health aim. Cardiovascular diseases are among the principal causes of disability and death in older persons, and therefore, preventive interventions for such diseases are a high priority. ${ }^{1-3}$

Low-dose aspirin is among the most widely used agents for the prevention of cardiovascular disease. ${ }^{4-8}$ Its efficacy has been established in secondary prevention trials, in which the benefits associated with reducing the rates of both myocardial infarction and ischemic stroke have appeared to outweigh the risk of hemorrhage.,10 In primary prevention trials, involving participants in whom the risk of cardiovascular disease was typically lower than the risk seen in secondary prevention trials, the risks and benefits of low-dose aspirin have been more finely balanced. The role of low-dose aspirin as a primary prevention strategy is debated. ${ }^{11-13}$

In elderly populations, the risk of cardiovascular disease is higher and the potential benefits of aspirin may accordingly be greater than in younger populations. However, an increased risk of bleeding has also been observed in the elderly age group. ${ }^{10,14-17}$ Because a limited number of older persons have been included in previous primary prevention trials, the risk-benefit balance in this age group is unknown. ${ }^{18}$

In the primary analysis of the Aspirin in Reducing Events in the Elderly (ASPREE) trial, now published in the Journal, ${ }^{19,20}$ we report that daily use of low-dose aspirin did not prolong disabilityfree survival among the elderly. Here, we report findings from the ASPREE trial regarding the effect of aspirin on the prespecified secondary end points of cardiovascular disease and major hemorrhage. We also present analyses of the nonprespecified end point of major adverse cardiovascular events.

\section{METHODS}

\section{TRIAL DESIGN}

Details of the trial rationale and design have been reported previously. ${ }^{21-23}$ The protocol and statistical analysis plan are available with the full text of this article at NEJM.org. In brief, we conducted this randomized, double-blind, placebocontrolled clinical trial to evaluate the effect of daily use of $100 \mathrm{mg}$ of enteric-coated aspirin in community-dwelling older adults.

Bayer Pharma (Germany) provided the trial drug (aspirin) and placebo but had no other role in the trial. The Department of Epidemiology and Preventive Medicine at Monash University in Australia coordinated the data collection and was responsible for statistical analyses. Coordination of the trial and monitoring of sites was conducted by this department in Australia and by the Berman Center for Outcomes and Clinical Research in the United States.

The trial was approved by the ethics committee at each participating center, and all the participants provided written informed consent before enrollment. The trial funder (the National Institute on Aging) and an independent data and safety monitoring board, whose members had been appointed by the National Institute on Aging, reviewed reports on the accumulating data at regular intervals. Trial centers were randomly audited; a data-quality committee monitored for the completeness and accuracy of the data, and the independent data and safety monitoring board monitored for safety. All the authors vouch for the accuracy and completeness of the data and analyses and for the fidelity of the trial to the protocol.

\section{TRIAL PARTICIPANTS}

Eligible participants were community-dwelling adults from Australia and the United States who were 70 years of age or older (or $\geq 65$ years of age among blacks and Hispanics in the United States). Eligibility criteria are provided in Table S1 in the Supplementary Appendix, available at NEJM.org. Participants were required to be free from overt coronary heart disease, overt cerebrovascular disease, atrial fibrillation, a clinical diagnosis of dementia, clinically significant physical disability, a high risk of bleeding, anemia, and a known contraindication to or inability to take aspirin. Key exclusion criteria were the current regular use of an anticoagulant or antiplatelet medication other than aspirin, a systolic blood pressure of $180 \mathrm{~mm} \mathrm{Hg}$ or more or a diastolic blood pressure of $105 \mathrm{~mm} \mathrm{Hg}$ or more, a medical indication for or contraindication to regular aspirin therapy, or the presence of a condition that, in the opinion of the primary care physician, 
was likely to result in death within 5 years. Participants were allowed to take other nonsteroidal antiinflammatory drugs (NSAIDs), with the recommendation to take the lowest dose for the shortest duration necessary.

\section{TRIAL PROCEDURES}

Participants who had a rate of adherence to pill ingestion, as assessed by pill count, of $80 \%$ or greater during a 1-month placebo run-in phase were randomly assigned, in a 1:1 ratio, to receive aspirin or placebo. Randomization was stratified according to trial center and age (65 to 79 years or $\geq 80$ years). Annual in-person visits and medicalrecord reviews were supplemented by regular telephone calls to encourage retention in the trial and facilitate the collection of clinical data (Table S2 in the Supplementary Appendix).

Trial participants, investigators, and general practitioner associate investigators were unaware of the trial-group assignments until the publication of this article. Adherence to the trial intervention was assessed annually by means of tablet counts on returned bottles of aspirin or placebo.

Committees whose members were unaware of the trial-group assignments were responsible for adjudication of all potential clinical end-point events. Descriptions of the definitions and processes used for adjudication are provided in the Supplementary Appendix. Additional information regarding the adjudication of major hemorrhagic events has been published previously. ${ }^{24}$ Data on causes of death are provided in a separate article in the Journal. ${ }^{20}$

\section{CARDIOVASCULAR EVENTS}

A prespecified secondary end point of the trial was cardiovascular disease, which was a composite of fatal coronary heart disease, nonfatal myocardial infarction, fatal or nonfatal stroke, or hospitalization for heart failure. The individual components of this end point were not prespecified as separate end points but were evaluated in a post hoc analysis to assist in the interpretation of the composite end point.

Fatal coronary heart disease was defined as death from myocardial infarction, sudden cardiac death, or any other death in which the underlying cause was considered to be coronary heart disease. Fatal stroke was defined as any death in which the underlying cause was an obstruction or rupture in the intracranial or extra- cranial cerebral arterial system. Fatal cardiovascular disease was defined as any death in which the underlying cause was coronary heart disease or stroke.

The definition of nonfatal myocardial infarction was based on joint guidelines of the European Society of Cardiology and the American College of Cardiology. ${ }^{25}$ Hospitalization for heart failure was defined as any unplanned stay, overnight or longer, in a hospital environment (emergency department, observation unit, or inpatientcare unit) or a similar facility, for which the principal reason for admission was heart failure. The definition of nonfatal stroke was based on the World Health Organization definition of rapidly developing clinical signs of focal or global disturbance of cerebral function lasting more than 24 hours (unless interrupted by surgery or death), with no apparent cause other than ischemic or hemorrhagic cerebrovascular disease. ${ }^{26}$ In both Australia and the United States, source documentation - including clinical notes, hospitalization records, and imaging studies (computed tomographic scans or magnetic resonance images) - was requested for events that were thought to be potential end-point events.

The nonprespecified end point of major adverse cardiovascular events was a composite of fatal coronary heart disease (excluding death from heart failure), nonfatal myocardial infarction, or fatal or nonfatal ischemic stroke. This end point included the conditions related to ischemia and thrombosis that are most likely to be affected favorably by low-dose aspirin.

\section{MAJOR HEMORRHAGIC EVENTS}

Another prespecified secondary end point was major hemorrhage, which was a composite of hemorrhagic stroke, symptomatic intracranial bleeding, or clinically significant extracranial bleeding. Clinically significant extracranial bleeding was defined as bleeding that led to transfusion, hospitalization, prolongation of hospitalization, surgery, or death.

\section{STATISTICAL ANALYSIS}

In intention-to-treat analyses, Cox proportionalhazards models were used to compare the aspirin group with the placebo group with regard to time-to-event end points. Cause-specific hazards were compared between groups, with deaths from causes other than those included in the end 
point of interest treated as censoring events. Confidence intervals were not adjusted for multiple comparisons, and $\mathrm{P}$ values are not presented for secondary or nonprespecified end points, except for major hemorrhage as a safety end point. Proportional-hazards assumptions were tested as a null hypothesis of a zero slope in a regression model of scaled Schoenfeld residuals against time; all $\mathrm{P}$ values were found to be greater than 0.1 , indicating satisfaction of the assumption for all end points. Cumulative incidences were used to show event risk. The cumulative incidences were based on competing-risks regression models, which were stratified according to trial group and which allowed for the competing risk of death from causes other than those included in the end point of interest. ${ }^{27}$

Subgroups of potential relevance to the risk of cardiovascular disease that were specified in the statistical analysis plan included sex, age (younger than the median age vs. the median age or older), country of residence (Australia vs. the United States), race or ethnic group (white in Australia, white in the United States, black, Hispanic, or other), smoking (never smoked, former smoker, or current smoker), body-mass index (the weight in kilograms divided by the square of the height in meters; $<20$ [underweight], 20 to 24 [normal weight], 25 to 29 [overweight], or $\geq 30$ [obese]), previous regular use of aspirin (yes vs. no), and the presence of diabetes, hypertension, and dyslipidemia at baseline (yes vs. no, for each condition). ${ }^{23}$ Nonprespecified subgroups that were also considered to be of interest included the number of cardiovascular risk factors (diabetes, hypertension, dyslipidemia, and current or former smoking) that were present ( 0 or 1,2 , or 3 or 4 ), the presence of chronic kidney disease (yes vs. no), and the use of statins or NSAIDs at randomization (yes vs. no, for each type of drug). A nonprespecified subgroup of potential relevance to the risk of major hemorrhage was the use of proton-pump inhibitors at randomization (yes vs. no). Interaction terms in Cox proportionalhazards models were used to test for heterogeneity of effect between subgroups.

RESULTS

PARTICIPANTS AND FOLLOW-UP

From March 2010 through December 2014, a total of 19,114 persons were enrolled in the trial and underwent randomization (9525 participants to the aspirin group and 9589 to the placebo group) (Fig. S1 in the Supplementary Appendix). The trial participants had a median age of 74 years at randomization, and 56\% were women (Table 1). A total of $87 \%$ were Australian residents and $13 \%$ were U.S. residents. The two trial groups had similar cardiovascular risk profiles. At trial entry, one third of the participants reported use of statins and 14\% reported regular use of NSAIDs.

The intervention phase ceased on June 12, 2017. All analyses were restricted to events that occurred through that date. The median followup was 4.7 years; $1.5 \%$ of the participants in the aspirin group and $1.6 \%$ of those in the placebo group had been lost to follow-up by the end of the trial, and $1.2 \%$ of the participants in each group had withdrawn consent (Fig. S1 in the Supplementary Appendix). In the final 12 months of the trial, $62 \%$ of the participants in the aspirin group and $64 \%$ of those in the placebo group were still taking the assigned trial intervention.

\section{CARDIOVASCULAR EVENTS}

Rates of cardiovascular events are shown in Table 2 and Figure 1, and further details, including data on subclassification of the events, are provided in Table S3 in the Supplementary Appendix. The rate of the prespecified secondary end point of cardiovascular disease did not differ significantly between the aspirin group and the placebo group (10.7 events per 1000 person-years of follow-up and 11.3 events per 1000 personyears, respectively; hazard ratio, 0.95 ; $95 \%$ confidence interval [CI], 0.83 to 1.08).

The rate of major adverse cardiovascular events was 7.8 events per 1000 person-years in the aspirin group and 8.8 events per 1000 personyears in the placebo group (hazard ratio, 0.89; $95 \%$ CI, 0.77 to 1.03) (Table 2, and Fig. S2 in the Supplementary Appendix). Individual rates of myocardial infarction, ischemic stroke, fatal cardiovascular disease, and hospitalization for heart failure were similar in the two groups (Table 2, and Figs. S3 and S4 in the Supplementary Appendix).

There was no evidence of a differential effect of aspirin on the risk of cardiovascular disease in any analyses of the prespecified subgroups or in post hoc analyses of subgroups of potential relevance to the risk of cardiovascular disease (Figs. S5 and S6 in the Supplementary Appendix). There was also no evidence of an interaction 
between trial group and any of the subgroups with regard to the end point of major adverse cardiovascular events (Figs. S7 and S8 in the Supplementary Appendix).

\section{MAJOR HEMORRHAGIC EVENTS}

Rates of major hemorrhagic events are shown in Table 3, cumulative incidences are shown in Figure 2, and further details, including data on subclassification of the events, are provided in Table S4 in the Supplementary Appendix. The rate of major hemorrhage was 8.6 events per 1000 person-years in the aspirin group, as compared with 6.2 events per 1000 person-years in the placebo group (hazard ratio, 1.38; 95\% CI, 1.18 to $1.62 ; \mathrm{P}<0.001)$. The progressive increase in the cumulative incidence of major hemorrhage across the trial follow-up period indicates that the risk of bleeding persisted throughout the course of therapy (Fig. 2). The rate of fatal hemorrhage was less than 1 event per 1000 person-years in each group.

Gastrointestinal bleeding accounted for just less than half the major hemorrhagic events. The higher risk of upper gastrointestinal bleeding with aspirin than with placebo was particularly pronounced (hazard ratio, 1.87; 95\% CI, 1.32 to 2.66) (Table 3). The risk of intracranial bleeding was also higher with aspirin than with placebo (hazard ratio, 1.50; 95\% CI, 1.11 to 2.02) (Fig. S9 in the Supplementary Appendix), and this finding was reflected across all subtypes of intracranial bleeding (Table 3). There was no evidence of a differential effect of aspirin on the risk of bleeding in any subgroup analysis, except for the possibility of a less harmful effect with increasing age (Figs. S10 and S11 in the Supplementary Appendix).

\section{DISCUSSION}

The ASPREE trial showed that, among elderly participants, the use of low-dose aspirin did not result in a significantly lower rate of the primary end point of disability-free survival (a composite that integrated the risks and benefits of aspirin) than placebo after a median follow-up of 4.7 years. ${ }^{19}$ On the basis of the results of previous trials, it was anticipated that benefits of aspirin treatment might arise from a reduction in the rate of cardiovascular events..$^{28-35}$ However, in this trial, the rate of the prespecified secondary end point of cardiovascular disease (a composite that
Table 1. Demographic Characteristics, Cardiovascular Risk Factors, and Treatment of the Participants at Randomization.*

\begin{tabular}{|c|c|c|}
\hline Variable & $\begin{array}{l}\text { Aspirin } \\
(\mathrm{N}=9525)\end{array}$ & $\begin{array}{l}\text { Placebo } \\
\text { ( } N=9589)\end{array}$ \\
\hline & \multicolumn{2}{|c|}{ no. (\%) } \\
\hline Male sex & $4152(44)$ & $4179(44)$ \\
\hline Age $\geq 74 \mathrm{yr}$ & $4806(50)$ & $4766(50)$ \\
\hline Black race $\dagger^{-}$ & $451(5)$ & $450(5)$ \\
\hline Obesetr & $2820(30)$ & $2857(30)$ \\
\hline \multicolumn{3}{|l|}{ Smoking } \\
\hline Current & $352(4)$ & $383(4)$ \\
\hline Former & $3909(41)$ & $3890(41)$ \\
\hline Never & $5264(55)$ & $5316(55)$ \\
\hline Diabetes』 & $1027(11)$ & $1030(11)$ \\
\hline Hypertension & $7065(74)$ & $7148(75)$ \\
\hline Dyslipidemia\| & $6159(65)$ & $6308(66)$ \\
\hline Chronic kidney disease & $2456(26)$ & $2464(26)$ \\
\hline \multicolumn{3}{|l|}{ Number of cardiovascular risk factors tit } \\
\hline 0 or 1 & $2935(31)$ & $2885(30)$ \\
\hline 2 & $3968(42)$ & $4049(42)$ \\
\hline 3 or 4 & $2622(28)$ & $2655(28)$ \\
\hline Previous regular aspirin usetr & $1053(11)$ & $1041(11)$ \\
\hline Statin use at trial entry $\int \mathbb{\int}$ & $3244(34)$ & $3226(34)$ \\
\hline $\begin{array}{l}\text { Use of nonsteroidal antiinflammatory drug } \\
\text { at trial entry }\end{array}$ & $1371(14)$ & $1342(14)$ \\
\hline Use of $\mathrm{H}_{2}$-receptor blocker at trial entry & $189(2)$ & $183(2)$ \\
\hline Use of proton-pump inhibitor at trial entry & $2340(25)$ & $2374(25)$ \\
\hline
\end{tabular}

* For all variables, odds ratios were between 0.67 and 1.50 (with an odds ratio of 1.50 as the prespecified limit for performing an adjusted analysis of end points) and there were no significant $(P>0.05)$ differences between the two trial groups.

$\dagger$ Data on race were reported by the participants.

$\mp$ Obese was defined as a body-mass index (the weight in kilograms divided by the square of the height in meters) of 30 or higher. Data were available for 19,035 participants; data on height, weight, or both were missing for 40 participants in the aspirin group and 39 in the placebo group.

$\int$ The presence of diabetes was based on participants' report of diabetes mellitus or a fasting glucose level of at least $126 \mathrm{mg}$ per deciliter $(\geq 7 \mathrm{mmol}$ per liter) or receipt of treatment for diabetes.

q Hypertension was defined as treatment for high blood pressure or a blood pressure of more than $140 / 90 \mathrm{~mm} \mathrm{Hg}$ at trial entry.

Dyslipidemia was defined as the receipt of cholesterol-lowering medication or as a serum cholesterol level of at least $212 \mathrm{mg}$ per deciliter $(\geq 5.5 \mathrm{mmol}$ per liter) in Australia and at least $240 \mathrm{mg}$ per deciliter ( $\geq 6.2 \mathrm{mmol}$ per liter) in the United States or as a low-density lipoprotein level of more than $160 \mathrm{mg}$ per deciliter (>4.1 mmol per liter).

$* *$ Chronic kidney disease was defined as an estimated glomerular filtration rate of less than $60 \mathrm{ml}$ per minute per $1.73 \mathrm{~m}^{2}$ or a ratio of albumin (in milligrams per liter) to creatinine (in millimoles per liter) in urine of 3 or more.

ti Cardiovascular risk factors were diabetes, hypertension, dyslipidemia, and current or former smoking.

Data were available for 19,112 participants; data were missing for 2 participants in the placebo group.

If Data for statin use included 483 participants (247 in the aspirin group and 236 in the placebo group) who were taking nonstatin lipid-lowering therapies. 


\begin{tabular}{|c|c|c|c|c|c|c|}
\hline \multirow[t]{2}{*}{ End Point } & \multirow{2}{*}{$\begin{array}{c}\text { Overall } \\
\text { ( } \mathrm{N}=19,114) \\
\text { no. of } \\
\text { participants } \\
\text { with event }\end{array}$} & \multicolumn{2}{|c|}{$\begin{array}{c}\text { Aspirin } \\
(\mathrm{N}=9525)\end{array}$} & \multicolumn{2}{|c|}{$\begin{array}{l}\text { Placebo } \\
\text { (N=9589) }\end{array}$} & \multirow[t]{2}{*}{$\begin{array}{c}\text { Hazard Ratio } \\
(95 \% \mathrm{Cl})\end{array}$} \\
\hline & & $\begin{array}{c}\text { no. of } \\
\text { participants } \\
\text { with event }\end{array}$ & $\begin{array}{c}\text { rate per } \\
1000 \text { person- } y r\end{array}$ & $\begin{array}{c}\text { no. of } \\
\text { participants } \\
\text { with event }\end{array}$ & $\begin{array}{c}\text { rate per } \\
1000 \text { person-yr }\end{array}$ & \\
\hline Cardiovascular disease $\dagger$ & 922 & 448 & 10.7 & 474 & 11.3 & $0.95(0.83-1.08)$ \\
\hline Major adverse cardiovascular event & 701 & 329 & 7.8 & 372 & 8.8 & $0.89(0.77-1.03)$ \\
\hline Fatal cardiovascular disease $\mathbb{Z}$ & 159 & 78 & 1.8 & 81 & 1.9 & $0.97(0.71-1.33)$ \\
\hline Hospitalization for heart failure & 171 & 88 & 2.1 & 83 & 1.9 & $1.07(0.79-1.44)$ \\
\hline Fatal or nonfatal myocardial infarction & 355 & 171 & 4.0 & 184 & 4.3 & $0.93(0.76-1.15)$ \\
\hline Fatal or nonfatal ischemic stroke & 315 & 148 & 3.5 & 167 & 3.9 & $0.89(0.71-1.11)$ \\
\hline
\end{tabular}

* Because some end points were composites, a participant who had events for more than one component of the composite (e.g., stroke and then acute myocardial infarction) would contribute only the first event that occurred to the composite end point but would contribute an event to the separate analyses of each component. Hence, summation of the number of events for separate components of a composite end point does not equate to the number of events for the composite end point. The confidence intervals shown in this table have not been adjusted for multiple comparisons, and inferences drawn from them may not be reproducible.

$\dagger$ Cardiovascular disease, a prespecified secondary end point, was a composite of fatal coronary heart disease (death from myocardial infarction, sudden cardiac death, or any other death in which the underlying cause was considered to be coronary heart disease), nonfatal myocardial infarction, fatal or nonfatal stroke (including hemorrhagic stroke), or hospitalization for heart failure.

Major adverse cardiovascular events, a nonprespecified end point, was a composite of fatal coronary heart disease (excluding death from heart failure), nonfatal myocardial infarction, or fatal or nonfatal ischemic stroke.

$\int$ Fatal cardiovascular disease was defined as any death from stroke (including hemorrhagic stroke) or coronary heart disease.

ๆ Data for ischemic stroke included cases that were adjudicated as ischemic stroke, cases for which stroke type was uncertain after adjudication, and cases of ischemic stroke with hemorrhagic transformation.

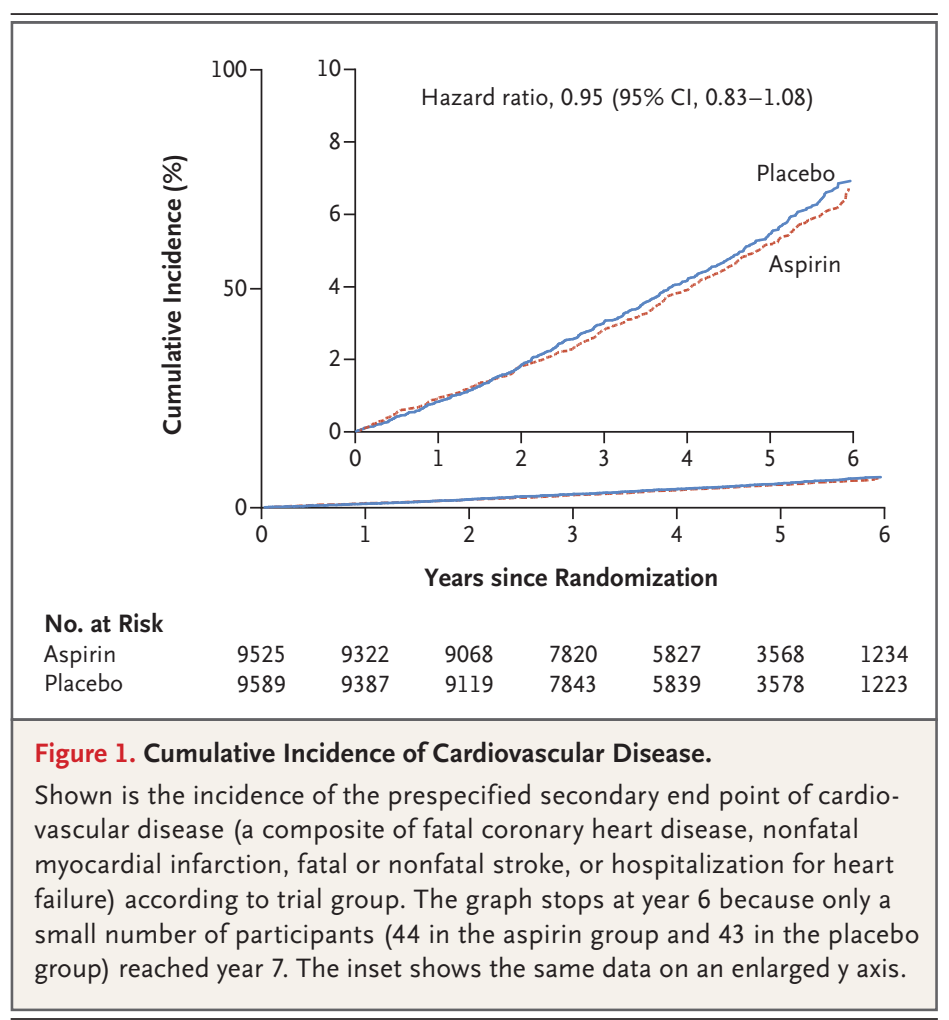

accounted for all cardiovascular events, including stroke due to intracranial hemorrhage and hospital admission for cardiac failure) was not significantly lower with low-dose aspirin than with placebo. The hazard ratio for this end point was 0.95 (95\% CI, 0.83 to 1.08), which rules out the possibility of a major protective effect of aspirin but is compatible with a more modest lowering of risk of up to $17 \%$. The rates of fatal cardiovascular disease and hospitalization for heart failure were similar in the two trial groups.

We also examined a nonprespecified end point of major adverse cardiovascular events, which was defined as a composite of fatal coronary heart disease, nonfatal myocardial infarction, or fatal or nonfatal ischemic stroke. This end point included the cardiovascular events that are most likely to be influenced favorably by aspirin. The rate of major adverse cardiovascular events did not differ significantly between the two groups. A similar conclusion was reached with regard to the individual rates of myocardial infarction and ischemic stroke.

Interpretation of these results should take into account the lower-than-expected rate of cardio- 


\begin{tabular}{|c|c|c|c|c|c|c|c|}
\hline \multirow[t]{2}{*}{ End Point } & \multirow{2}{*}{$\begin{array}{c}\text { Overall } \\
(\mathrm{N}=19,114) \\
\text { no. of } \\
\text { participants } \\
\text { with event }\end{array}$} & \multicolumn{2}{|c|}{$\begin{array}{c}\text { Aspirin } \\
(\mathrm{N}=9525)\end{array}$} & \multicolumn{2}{|c|}{$\begin{array}{l}\text { Placebo } \\
(\mathrm{N}=9589)\end{array}$} & \multirow[t]{2}{*}{$\begin{array}{c}\text { Hazard Ratio } \\
(95 \% \mathrm{CI})\end{array}$} & \multirow[t]{2}{*}{ P Value } \\
\hline & & $\begin{array}{l}\text { no. of } \\
\text { participants } \\
\text { with event }\end{array}$ & $\begin{array}{c}\text { rate per } \\
1000 \text { person-yr }\end{array}$ & $\begin{array}{l}\text { no. of } \\
\text { participants } \\
\text { with event }\end{array}$ & $\begin{array}{c}\text { rate per } \\
1000 \text { person-yr }\end{array}$ & & \\
\hline Major hemorrhage $†$ & 626 & 361 & 8.6 & 265 & 6.2 & $1.38(1.18-1.62)$ & $<0.001$ \\
\hline \multicolumn{8}{|l|}{ Intracranial bleeding } \\
\hline Any & 179 & 107 & 2.5 & 72 & 1.7 & $1.50(1.11-2.02)$ & - \\
\hline Hemorrhagic stroke & 77 & 43 & 1.0 & 34 & 0.8 & $1.27(0.81-2.00)$ & - \\
\hline Subdural or extradural hemorrhage & 61 & 39 & 0.9 & 22 & 0.5 & $1.79(1.06-3.02)$ & - \\
\hline Subarachnoid hemorrhaget & 32 & 18 & 0.4 & 14 & 0.3 & $1.30(0.64-2.60)$ & - \\
\hline \multicolumn{8}{|l|}{ Extracranial bleeding } \\
\hline Upper gastrointestinal bleeding & 137 & 89 & 2.1 & 48 & 1.1 & $1.87(1.32-2.66)$ & - \\
\hline Lower gastrointestinal bleeding & 127 & 73 & 1.7 & 54 & 1.3 & $1.36(0.96-1.94)$ & - \\
\hline Bleeding at another site $\mathbb{Z}$ & 189 & 101 & 2.4 & 88 & 2.1 & $1.16(0.87-1.54)$ & - \\
\hline \multicolumn{8}{|l|}{ Fatal bleeding } \\
\hline Fatal major hemorrhage & 52 & 28 & 0.7 & 24 & 0.6 & $1.18(0.68-2.03)$ & - \\
\hline Fatal hemorrhagic stroke & 26 & 13 & 0.3 & 13 & 0.3 & $1.01(0.47-2.17)$ & - \\
\hline
\end{tabular}

* Because some end points were composites, a participant who had events for more than one component of the composite (e.g., stroke and then acute myocardial infarction) would contribute only the first event that occurred to the composite end point but would contribute an event to the separate analyses of each component. Hence, summation of the number of events for separate components of a composite end point does not equate to the number of events for the composite end point. The confidence intervals shown in this table have not been adjusted for multiple comparisons, and inferences drawn from them may not be reproducible.

$\uparrow$ Major hemorrhage, a prespecified secondary end point, was a composite of hemorrhagic stroke, symptomatic intracranial bleeding, or extracranial bleeding that led to transfusion, hospitalization, prolonged hospitalization, surgery, or death.

$\uparrow$ Data for subarachnoid hemorrhage included 18 persons who had subarachnoid hemorrhage and 14 who had a subarachnoid hemorrhagic stroke.

$\int$ Bleeding at another site included hematuria, bleeding at a surgical site, bleeding after trauma, and epistaxis.

I Data for fatal major hemorrhage included deaths that were adjudicated to be from major hemorrhage.

vascular disease among the trial participants. In the trial protocol, the anticipated rate was 22.4 events per 1000 person-years. The observed rate was approximately half this estimate, most likely reflecting the relatively good health of the participant population at recruitment and the declining rate of cardiovascular disease in the two countries over time and across all age groups. ${ }^{36-39}$ Because of these factors, the absolute benefit that results from any proportionally lower rate of cardiovascular disease may be less than the benefit observed in studies from previous decades and is less likely than it had been to outweigh the risk of adverse events from aspirin.

This trial also showed that the risk of major hemorrhage was significantly higher with aspirin than with placebo. Major hemorrhagic events primarily involved upper gastrointestinal and intracranial bleeding. The relative effect of aspirin use, as compared with placebo, on the risk of major hemorrhage was constant over time, suggesting that persons who receive low-dose aspirin have a risk of bleeding that does not decline with continued use.

These two results - the absence of a large benefit on cardiovascular disease coupled with the higher risk of bleeding with the use of lowdose aspirin - are compatible with the results of a recent meta-analysis of eight primary prevention trials, predominantly involving adults younger than 70 years of age, which showed a $17 \%$ lower risk of nonfatal myocardial infarction and a $14 \%$ lower risk of stroke, coupled with a higher risk of serious bleeding, among participants who received aspirin than among those in control groups. ${ }^{33,40-47}$ As would be expected, the 


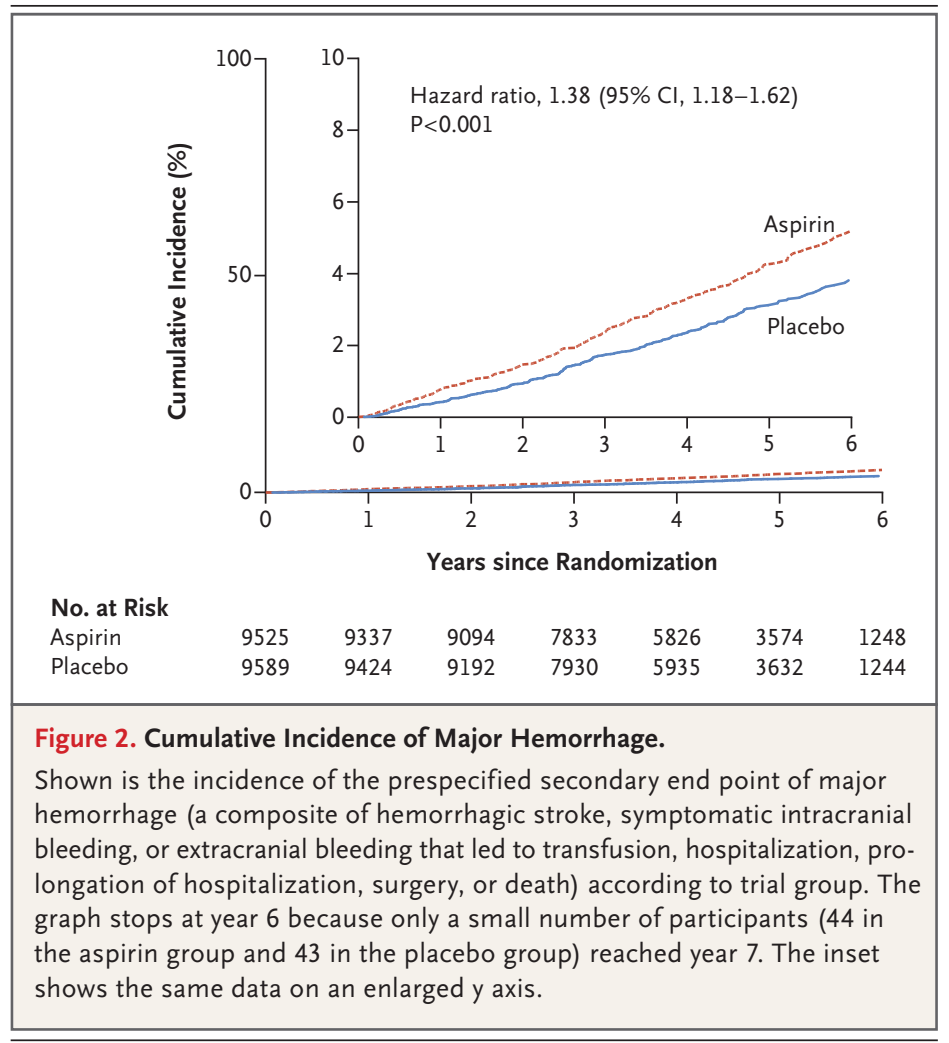

incidence of bleeding in this trial was substantially higher than the incidence in trials with younger participants. ${ }^{16,17,34}$ Because this trial enrolled healthy older persons from the general population, the results are likely to be broadly applicable to the healthy elderly, who are typically considered for primary prevention of cardiovascular disease. In contrast with most previous primary prevention trials, this trial did not enroll participants on the basis of elevated cardiovascular risk.

Current guidelines in the United States, Europe, and Australia have noted that there is limited evidence regarding the use of aspirin for primary prevention of cardiovascular disease in the elderly. ${ }^{48-50}$ Nevertheless, many millions of relatively healthy older persons in the United States and Australia take low-dose aspirin with the assumption that it will reduce the likelihood of future cardiovascular disease and stroke. Interpretation of the results of this trial should take into account the low percentage of participants (11\%) who had been regularly taking low-dose aspirin before entering the trial. The trial did not directly address the question of whether healthy older persons who have been taking aspirin for primary prevention should continue its use.

This trial has some limitations. First, by the end of the trial, only approximately two thirds of the participants were still taking the assigned trial intervention, and this adherence rate may have led to an underestimation of any benefit of aspirin on cardiovascular outcomes. However, the adherence rate was sufficiently high for an increased bleeding risk to be identified, and the rate was probably similar to that seen in clinical practice. ${ }^{51,52}$ Second, the end point of major adverse cardiovascular events is commonly used in trials of antithrombotic therapy but was not prespecified in this trial. However, the results for this end point were similar to those for the prespecified end point that included hemorrhagic stroke and hospitalization for heart failure.

In conclusion, in this randomized trial involving healthy elderly persons who did not have known cardiovascular disease, the use of lowdose aspirin resulted in a significantly higher risk of major hemorrhage and did not result in a significantly lower risk of cardiovascular disease than placebo.

Supported by a grant (U01AG029824) from the National Institute on Aging and the National Cancer Institute at the National Institutes of Health, by grants (334047 and 1127060) from the National Health and Medical Research Council of Australia, and by Monash University and the Victorian Cancer Agency.

Disclosure forms provided by the authors are available with the full text of this article at NEJM.org.

A data sharing statement provided by the authors is available with the full text of this article at NEJM.org.

We thank members of the National Institute on Aging and the data and safety monitoring board for comments on an earlier version of the manuscript; the trial staff in Australia and the United States; the participants who volunteered for this trial; and the general practitioners and staff of the medical clinics who cared for the participants.

\section{APPENDIX}

The authors' full names and academic degrees are as follows: John J. McNeil, M.B., B.S., Ph.D., Rory Wolfe, Ph.D., Robyn L. Woods, Ph.D., Andrew M. Tonkin, M.B., B.S., M.D., Geoffrey A. Donnan, M.B., B.S., M.D., Mark R. Nelson, M.B., B.S., Ph.D., Christopher M. Reid, Ph.D., M.P.H., Jessica E. Lockery, M.B., B.S., Brenda Kirpach, C.C.R.A., Elsdon Storey, M.B., B.S., D.Phil., Raj C. Shah, M.D., Jeff D. Williamson, M.D., M.H.S., Karen L. Margolis, M.D., M.P.H., Michael E. Ernst, Pharm.D., Walter P. Abhayaratna, M.B., B.S., Ph.D., Nigel Stocks, M.B., B.S., M.D., Sharyn M. Fitzgerald, Ph.D., M.P.H., Suzanne G. Orchard, Ph.D., Ruth E. Trevaks, Ph.D., Lawrence J. Beilin, M.D., Colin I. Johnston, M.B., B.S., M.D., Joanne Ryan, M.Biostat., Ph.D., Barbara Radziszewska, Ph.D., M.P.H., Michael Jelinek, M.B., B.S., M.D., Mobin Malik, M.D., Charles B. Eaton, M.D., Donna Brauer, Ph.D., Geoff Cloud, M.B., B.S., Erica M. Wood, 
M.B., B.S., Suzanne E. Mahady, M.B., B.S., Ph.D., Suzanne Satterfield, M.D., Dr.P.H., Richard Grimm, M.D., M.P.H., Ph.D., and Anne M. Murray, M.D.

The authors' affiliations are as follows: the Department of Epidemiology and Preventive Medicine, Monash University (J.J.M., R.W., R.L.W., A.M.T., M.R.N., C.M.R., J.E.L., E.S., S.M.F., S.G.O., R.E.T., C.I.J., J.R., E.M.W., S.E.M.), Baker Heart and Diabetes Institute (C.I.J.), the Department of Cardiology, St. Vincent's Hospital (M.J.), and the Department of Clinical Neurosciences, Central Clinical School, Monash University and Alfred Hospital (G.C.), Melbourne, and Florey Institute of Neuroscience and Mental Health, University of Melbourne, Parkville (G.A.D.), VIC, Menzies Institute for Medical Research, University of Tasmania, Hobart (M.R.N.), the School of Public Health, Curtin University (C.M.R.), and the School of Medicine, Royal Perth Hospital, University of Western Australia (L.J.B.), Perth, the College of Medicine, Biology and Environment, Australian National University, Canberra, ACT (W.P.A.), and the Discipline of General Practice, University of Adelaide, Adelaide, SA (N.S.) — all in Australia; the Berman Center for Outcomes and Clinical Research, Hennepin Healthcare Research Institute, Hennepin Healthcare (B.K., R.G., A.M.M.), HealthPartners Institute (K.L.M.), and the Division of Geriatrics, Department of Medicine, Hennepin Healthcare and the University of Minnesota (A.M.M.), Minneapolis, and the School of Nursing, Minnesota State University, Mankato (D.B.) - all in Minnesota; the Department of Family Medicine and Rush Alzheimer's Disease Center, Rush University Medical Center, Chicago (R.C.S.); Sticht Center on Aging and Alzheimer's Prevention, Section on Gerontology and Geriatric Medicine, Department of Internal Medicine, Wake Forest School of Medicine, Winston-Salem, NC (J.D.W.); the Department of Pharmacy Practice and Science, College of Pharmacy and Department of Family Medicine, Carver College of Medicine, University of Iowa, Iowa City (M.E.E.); the Division of Geriatrics and Clinical Gerontology, National Institute on Aging, Bethesda, MD (B.R.); the Department of Cardiovascular Medicine, Vascular Medicine Section, Cleveland Clinic, Cleveland (M.M.); the Center for Primary Care and Prevention, Brown University, Providence, RI (C.B.E.); and the University of Tennessee Health Science Center, Memphis (S.S.).

\section{REFERENCES}

1. Yazdanyar A, Newman AB. The burden of cardiovascular disease in the elderly: morbidity, mortality, and costs. Clin Geriatr Med 2009;25:563-577, vii.

2. Australian Bureau of Statistics. 3303.0 - causes of death, Australia, 2016 (http:// www.abs.gov.au/AUSSTATS/abs@.nsf/ DetailsPage/3303.02016? OpenDocument). 3. Centers for Disease Control and Pre vention. LCWK3 - deaths, percent of total deaths, and death rates for the 15 leading causes of death in selected age groups, by race and Hispanic origin, and sex: United States, 2016 (https://www.cdc .gov/nchs/data/dvs/lcwk/lcwk3_hr_2016 .pdf).

4. Hennekens CH, Dyken ML, Fuster V. Aspirin as a therapeutic agent in cardiovascular disease: a statement for healthcare professionals from the American Heart Association. Circulation 1997;96: 2751-3.

5. Ajani UA, Ford ES, Greenland KJ, Giles WH, Mokdad AH. Aspirin use among U.S. adults: Behavioral Risk Factor Surveillance System. Am J Prev Med 2006;30:74-7. 6. Ittaman SV, VanWormer JJ, Rezkalla $\mathrm{SH}$. The role of aspirin in the prevention of cardiovascular disease. Clin Med Res 2014;12:147-54.

7. Duffy D, Kelly E, Trang A, Whellan D, Mills G. Aspirin for cardioprotection and strategies to improve patient adherence. Postgrad Med 2014;126:18-28.

8. $\mathrm{Gu} \mathrm{Q}$, Dillon $\mathrm{CF}$, Eberhardt MS, Wright JD, Burt VL. Preventive aspirin and other antiplatelet medication use among U.S. adults aged $\geq 40$ years: data from the National Health and Nutrition Examination Survey, 2011-2012. Public Health Rep 2015;130:643-54.

9. Gorelick PB, Weisman SM. Risk of hemorrhagic stroke with aspirin use: an update. Stroke 2005;36:1801-7.

10. Antithrombotic Trialists' (ATT) Collaboration. Aspirin in the primary and secondary prevention of vascular disease: collaborative meta-analysis of individual participant data from randomised trials. Lancet 2009;373:1849-60.

11. Guirguis-Blake JM, Evans CV, Senger CA, Rowland MG, O'Connor EA, Whitlock EP. Aspirin for the primary prevention of cardiovascular events: a systematic evidence review for the U.S. Preventive Services Task Force. Report no. 13-05195-EF-1. Rockville, MD: Agency for Healthcare Research and Quality, 2015.

12. Capodanno D, Angiolillo DJ. Aspirin for primary cardiovascular risk prevention and beyond in diabetes mellitus. Circulation 2016;134:1579-94.

13. Lei H, Gao Q, Liu S-R, Xu J. The benefit and safety of aspirin for primary prevention of ischemic stroke: a meta-analysis of randomized trials. Front Pharmacol 2016; $7: 440$.

14. De Berardis G, Lucisano G, D'Ettorre A, et al. Association of aspirin use with major bleeding in patients with and without diabetes. JAMA 2012;307:2286-94.

15. Andreotti F, Rocca B, Husted S, et al. Antithrombotic therapy in the elderly: expert position paper of the European Society of Cardiology Working Group on Thrombosis. Eur Heart J 2015;36:3238-49. 16. Whitlock EP, Burda BU, Williams SB, Guirguis-Blake JM, Evans CV. Bleeding risks with aspirin use for primary prevention in adults: a systematic review for the U.S. Preventive Services Task Force. Ann Intern Med 2016;164:826-35.

17. Li L, Geraghty OC, Mehta Z, Rothwell PM. Age-specific risks, severity, time course, and outcome of bleeding on longterm antiplatelet treatment after vascular events: a population-based cohort study. Lancet 2017;390:490-9.

18. Nelson MR, Liew D, Bertram M, Vos T. Epidemiological modelling of routine use of low dose aspirin for the primary prevention of coronary heart disease and stroke in those aged $\geq 70$. BMJ 2005;330: 1306.

19. McNeil JJ, Woods RL, Nelson MR, et al. Effect of aspirin on disability-free survival in the healthy elderly. N Engl J Med. DOI: 10.1056/NEJMoa1800722.

20. McNeil JJ, Nelson MR, Woods RL, et al. Effect of aspirin on all-cause mortality in the healthy elderly. N Engl J Med. DOI: 10.1056/NEJMoa1803955.

21. Nelson M, Reid C, Beilin L, et al. Rationale for a trial of low-dose aspirin for the primary prevention of major adverse cardiovascular events and vascular dementia in the elderly: Aspirin in Reducing Events in the Elderly (ASPREE). Drugs Aging 2003;20:897-903.

22. ASPREE Investigator Group. Study design of ASPirin in Reducing Events in the Elderly (ASPREE): a randomized, controlled trial. Contemp Clin Trials 2013;36: 555-64.

23. Wolfe R, Murray AM, Woods RL, et al. The ASPirin in Reducing Events in the Elderly trial: statistical analysis plan. Int J Stroke 2018;13:335-8.

24. Margolis KL, Mahady SE, Nelson MR, et al. Development of a standardized definition for clinically significant bleeding in the ASPirin in Reducing Events in the Elderly (ASPREE) trial. Contemp Clin Trials Commun 2018;11:30-6.

25. Alpert JS, Thygesen K, Antman E, Bassand JP. Myocardial infarction redefined - a consensus document of The Joint European Society of Cardiology/American College of Cardiology Committee for the redefinition of myocardial infarction. J Am Coll Cardiol 2000;36:959-69.

26. Stroke - 1989: recommendations on stroke prevention, diagnosis, and therapy: report of the WHO Task Force on Stroke and other Cerebrovascular Disorders. Stroke 1989;20:1407-31.

27. Andersen PK, Geskus RB, de Witte T, Putter H. Competing risks in epidemiol- 
ogy: possibilities and pitfalls. Int J Epidemiol 2012;41:861-70.

28. Bartolucci AA, Tendera M, Howard G. Meta-analysis of multiple primary prevention trials of cardiovascular events using aspirin. Am J Cardiol 2011;107:1796-801. 29. Berger JS, Lala A, Krantz MJ, Baker GS, Hiatt WR. Aspirin for the prevention of cardiovascular events in patients without clinical cardiovascular disease: a metaanalysis of randomized trials. Am Heart J 2011;162:115-24.e2.

30. Raju N, Sobieraj-Teague M, Hirsh J, O'Donnell M, Eikelboom J. Effect of aspirin on mortality in the primary prevention of cardiovascular disease. Am J Med 2011;124:621-9.

31. Raju NC, Eikelboom JW. The aspirin controversy in primary prevention. Curr Opin Cardiol 2012;27:499-507.

32. Xie M, Shan Z, Zhang Y, et al. Aspirin for primary prevention of cardiovascular events: meta-analysis of randomized controlled trials and subgroup analysis by sex and diabetes status. PLoS One 2014;9(10): e90286.

33. Guirguis-Blake JM, Evans CV, Senger CA, O'Connor EA, Whitlock EP. Aspirin for the primary prevention of cardiovascular events: a systematic evidence review for the U.S. Preventive Services Task Force. Ann Intern Med 2016;164:804-13.

34. Mora S, Manson JE. Aspirin for primary prevention of atherosclerotic cardiovascular disease: advances in diagnosis and treatment. JAMA Intern Med 2016; 176:1195-204.

35. Raju N, Sobieraj-Teague M, Bosch J, Eikelboom JW. Updated meta-analysis of aspirin in primary prevention of cardiovascular disease. Am J Med 2016;129(5): e35-e36.

36. Trends in coronary heart disease mortality: age groups and populations. Canberra: Australian Institute of Health and Welfare, May 8, 2014 (https://www.aihw.gov .au/reports/heart-stroke-vascular-disease/ trends-in-coronary-heart-disease/contents/ summary).

37. Waters AM, Trinh L, Chau T, Bourchie M, Moon L. Latest statistics on cardiovascular disease in Australia. Clin Exp Pharmacol Physiol 2013;40:347-56.

38. Weir HK, Anderson RN, Coleman King SM, et al. Heart disease and cancer deaths - trends and projections in the United States, 1969-2020. Prev Chronic Dis 2016; 13:E157.

39. Mensah GA, Wei GS, Sorlie PD, et al. Decline in cardiovascular mortality: possible causes and implications. Circ Res 2017;120:366-80.

40. Saito Y, Okada S, Ogawa H, et al. Lowdose aspirin for primary prevention of cardiovascular events in patients with type 2 diabetes mellitus: 10-year follow-up of a randomized controlled trial. Circulation 2017;135:659-70

41. Belch J, MacCuish A, Campbell I, et al. The Prevention of Progression of Arterial Disease and Diabetes (POPADAD) trial factorial randomised placebo controlled trial of aspirin and antioxidants in patients with diabetes and asymptomatic peripheral arterial disease. BMJ 2008;337:a1840. 42. Ogawa $H$, Nakayama $M$, Morimoto $T$, et al. Low-dose aspirin for primary prevention of atherosclerotic events in patients with type 2 diabetes: a randomized controlled trial. JAMA 2008;300:2134-41. 43. Fowkes FG, Price JF, Stewart MC, et al. Aspirin for prevention of cardiovascular events in a general population screened for a low ankle brachial index: a randomized controlled trial. JAMA 2010;303:841-8. 44. Ikeda Y, Shimada K, Teramoto T, et al. Low-dose aspirin for primary prevention of cardiovascular events in Japanese patients 60 years or older with atherosclerotic risk factors: a randomized clinical trial. JAMA 2014;312:2510-20.

45. Uchiyama $S$, Ishizuka $N$, Shimada $K$ et al. Aspirin for stroke prevention in elderly patients with vascular risk factors
Japanese Primary Prevention Project. Stroke 2016;47:1605-11.

46. Steering Committee of the Physicians' Health Study Research Group. Final report on the aspirin component of the ongoing Physicians' Health Study. N Engl J Med 1989;321:129-35.

47. Hansson L, Zanchetti A, Carruthers SG, et al. Effects of intensive blood-pressure lowering and low-dose aspirin in patients with hypertension: principal results of the Hypertension Optimal Treatment (HOT) randomised trial. Lancet 1998;351:1755-62. 48. Nelson MR, Doust JA. Primary prevention of cardiovascular disease: new guidelines, technologies and therapies. Med J Aust 2013;198:606-10.

49. Bibbins-Domingo K. Aspirin use for the primary prevention of cardiovascular disease and colorectal cancer: U.S. Preventive Services Task Force recommendation statement. Ann Intern Med 2016;164:836-45.

50. Piepoli MF, Hoes AW, Agewall S, et al. 2016 European Guidelines on cardiovascular disease prevention in clinical practice: the Sixth Joint Task Force of the European Society of Cardiology and Other Societies on Cardiovascular Disease Prevention in Clinical Practice (constituted by representatives of 10 societies and by invited experts) developed with the special contribution of the European Association for Cardiovascular Prevention \& Rehabilitation (EACPR). Eur Heart J 2016;37:231581.

51. Singh G, Arora G, Mannalithara A, Mithal A, Sehgal A, Triadafilopoulos G. Alarmingly poor adherence to low-dose aspirin: a large population-based study. Eur Heart J 2013;34:Suppl 1:2522. abstract. 52. Malayala SV, Raza A. Compliance with USPSTF recommendations on aspirin for prevention of cardiovascular disease in men. Int J Clin Pract 2016;70:898906.

Copyright (c) 2018 Massachusetts Medical Society. 